Diabetologia (1993) 36: 1185-1190

\title{
Hepatic glucose production during intraperitoneal and intravenous closed-loop insulin regulation of blood glucose in Type 1 (insulin-dependent) diabetic patients
}

\author{
J. -J. Robert ${ }^{1}$, D. Chauvet ${ }^{1}$, D. Darmaun ${ }^{2}$, H. Leblanc ${ }^{3}$ \\ ${ }^{1}$ Department of Paediatric Endocrinology and Diabetology, Enfants-Malades Hospital, Paris, France \\ ${ }^{2}$ INSERM U 290, Saint-Lazare Hospital, Paris, France \\ ${ }^{3}$ Department of Diabetology, Saint-Louis Hospital, Paris, France
}

\begin{abstract}
Summary. Intraperitoneal infusion of insulin should be more physiological than intravenous insulin since part of the insulin is directed toward the portal vein, which allows the liver to retain its major role in glucose homeostasis. The regulation of hepatic glucose production during the intraperitoneal and intravenous infusions of insulin were compared in eight Type 1 (insulin-dependent), C-peptide-deficient diabetic patients. Primed, continuous infusions of $\left[6,6-{ }^{2} \mathrm{H}\right]$ glucose were given in the postabsorptive state and during continuous infusion of unlabelled glucose at 1.5 and $4 \mathrm{mg} / \mathrm{kg}$. $\mathrm{min}$, while normoglycaemia was maintained by closed-loop intraperitoneal and intravenous insulin delivery. During all three periods, plasma glucose concentrations remained near normal (variations $3.8-6.1 \%$ ). The insulin infusion rates required for normal plasma glucose concentrations were essentially the same for the intravenous and intraperitoneal routes in all cases, although the variations were greater with intraperitoneal in-
\end{abstract}

sulin. Plasma free-insulin levels were only slightly, non-significantly lower with intraperitoneal infusion than with intravenous infusion. Hepatic glucose production was significantly lower with intraperitoneal insulin during all three conditions: basal: $1.71 \pm 0.14$, i.p. vs $2.37 \pm 0.26 \mathrm{mg} / \mathrm{kg} \cdot \mathrm{min}$, i.v.; $1.5 \mathrm{mg} / \mathrm{kg} \cdot \min$ glucose infusion: $0.49 \pm 0.23$, i.p. vs $0.88 \pm 0.18 \mathrm{mg} / \mathrm{kg} \cdot \mathrm{min}$, i. v.; $4 \mathrm{mg} / \mathrm{kg} \cdot \min$ glucose infusion: $0.31 \pm 0.10$, i. p. vs $0.56 \pm 0.12 \mathrm{mg} / \mathrm{kg} \cdot \mathrm{min}$, i. v.. These results, obtained with steady-state conditions for plasma glucose, isotopic plasma glucose enrichments and unlabelled glucose infusion rates, suggest that better control of hepatic glucose production leading to normoglycaemia was achieved with the intraperitoneal infusion.

Key words: Type 1 (insulin-dependent) diabetes mellitus, intraperitoneal insulin, closed-loop blood glucose control, hepatic glucose production, stable isotope labelled glucose.
Intraperitoneal infusion has been used successfully for the delivery of insulin by continuous external [1] or implanted $[2,3]$ open-loop infusers. The intraperitoneal route appears to be technically more reliable for these implanted devices than the intravenous infusion [3]. It also has physiological advantages, since part of the intraperitoneal insulin is absorbed and passes into the portal vein [4-7], allowing the liver to retain its primordial role in the regulation of blood glucose $[8,9]$ and limiting the hyperinsulinaemia that can result from peripheral insulin injections $[10,11]$. Most studies on animals have compared the intravenous and intraportal administrations of insulin, with insulin being provided either by an exogenous infusion [11-18] or by a pancreas or islet [19-21] transplant. The apparent effects on hepatic and peripheral glucose metabolism have been contradictory. Some studies found no difference between the intraportal and the intravenous routes $[11,13,15,17,18,20]$. Others found that the intraportal route had metabolic advantages [11, 14, 19, 21]. Thus, it is not clear whether restoring the portal-periphe- ral insulin gradient has any real physiological benefit [22]. Peripheral insulin has been suggested to be as important as intraportal insulin for suppressing hepatic glucose production $[17,23]$. However, the lower peripheral insulin concentrations attained with intraportal insulin should ensure that its peripheral effects are less than those of intravenous insulin. Only a few studies $[24,25]$ have documented the potential metabolic advantages of the intraperitoneal insulin infusion in man. The present study compares the effects of intraperitoneal and intravenous insulin on the regulation of hepatic glucose production in Type 1 (insulin-dependent) diabetic patients. All measurements were made using a closed-loop system and stable isotopically labelled glucose. The diabetic subjects were in a basal state and were continuously infused with unlabelled glucose at physiological levels. 


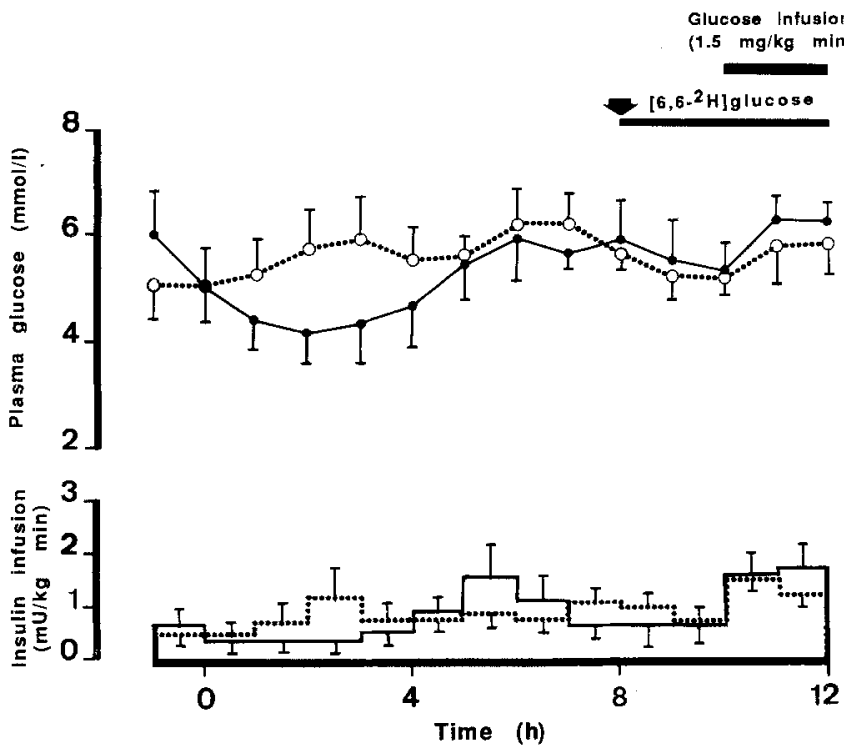

Fig. 1. The experimental protocol for infusing deuterated-glucose in the postabsorptive state and during the infusion of unlabelled glu cose at $1.5 \mathrm{mg} / \mathrm{kg} \cdot \mathrm{min}$, in Type 1 diabetic patients maintained at nor moglycaemia by closed-loop intravenous $(\ldots \ldots)$ or intraperitoneal $(\longrightarrow$ ) insulin infusion. Values are means \pm SEM

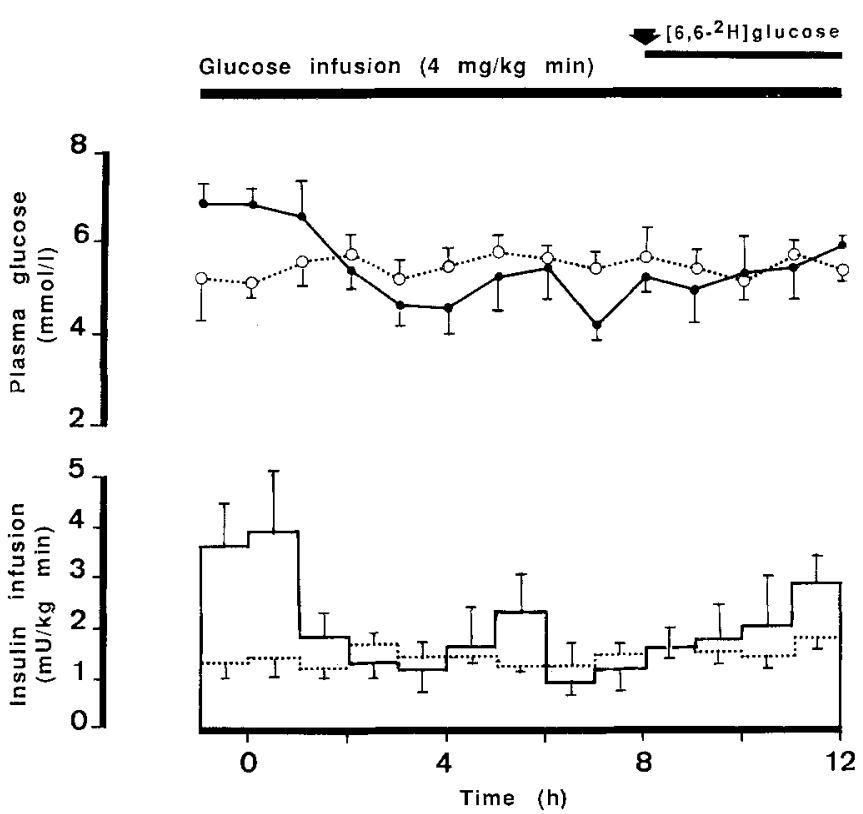

Fig.2. The experimental protocol for infusing deuterated-glucose during the infusion of unlabelled glucose at $4 \mathrm{mg} / \mathrm{kg} \cdot \mathrm{min}$, in Type 1 diabetic patients maintained at normoglycaemia by closed-loop intravenous $(\ldots \ldots)$ or intraperitoneal $(-)$ insulin infusion. Values are means \pm SEM

\section{Subjects and methods}

The experiments were performed on eight men with Type 1 diabetes aged $20-55$ years (mean $\pm \mathrm{SD}=34.6 \pm 9.9$ years). They had been treated by subcutaneous insulin injection for 1.5 to 39 years $(13.6 \pm 13.5$ years $)$. None of them had any residual endogenous insulin secretion, as demonstrated by lack of plasma C-peptide response after stimulation by intravenous injection of $1 \mathrm{mg}$ glucagon. Mean body mass index was $103.7 \pm 9.2 \%$ of ideal [26]. They were in good health as documented by their medical history, physical exam- ination, electrocardiogram, and routine blood and urine biochemical screening. They had normal blood pressures and no signs of nephropathy (albuminuria, high blood creatinine and/or urea nitrogen levels). However, four of the men had varying degrees of retinopathy, and two had signs of peripheral neuropathy. None of the subjects was taking any medication other than insulin. The subjects continued to eat their usual diet before the experiment, but the pattern and type of food consumed during the week before admission was recorded by a dietitian. Estimated calorie intake was 2000 $4000 \mathrm{kcal} /$ day $(2600 \pm 780 \mathrm{kcal} / \mathrm{day})$ and carbohydrate intake 240 $440 \mathrm{~g} /$ day $(310 \pm 95 \mathrm{~g} /$ day), i. e. $48 \%$ of total calorie intake.

All subjects were fully informed of the purpose and potential risks of the experiment and gave their written consent to participate. The experimental procedure was approved by the Ethical Committee of the Université Lariboisière Saint-Louis, Paris.

$\left[6,6{ }^{2} \mathrm{H}\right]$ glucose $\left(98\right.$ atoms $\left.\%{ }^{2} \mathrm{H}\right)$ was purchased from the Centre d'Etudes Atomiques, Saclay, France. Chemical, isotopic and optical purity were checked by conventional gas chromatographic and mass spectrometric analysis. Isotope solutions were pyrogen-free, and were prepared sterile in $0.9 \% \mathrm{NaCl}$.

An intraperitoneal catheter $(1.3 / 450 \mathrm{~mm}$ Nutricath; Vygon, Ecouen, France) was inserted into the subumbilical area through a Portnoy trocar after local lidocaine anaesthesia. X-ray examination confirmed that the catheter was in the submesocolic position [27]. The usual insulin treatment was suspended for the following 2 days and rapid-acting insulin was infused intraperitoneally by means of an open-loop insulin infusion system (Nordisk Infusor; Nordisk, Gentofte, Denmark).

At 08.00 hours on the day of the study, an automated glucose control insulin infusion system (Glucose Controller, Biostator; Life Sciences Instruments, Elkhart, Ind., USA) was connected to the patient. Two smooth catheters ( 20 gauge $/ 32 \mathrm{~mm}$ ) were inserted into forearm veins for constant monitoring of blood glucose and blood collection. A third catheter (17 gauge $/ 30 \mathrm{~cm}$ ) was placed in an antecubital vein for infusion of insulin and glucose solutions. The infusion tubing was set up so that the intravenous and intraperitoneal catheters could be alternately infused with $0.9 \% \mathrm{NaCl}$ and diluted insulin solution $(1.3 \mathrm{IU} / \mathrm{ml}$ in $0.9 \% \mathrm{NaCl}$ without added albumin). The intraperitoneal catheter was rinsed free of any $100 \mathrm{IU} / \mathrm{ml}$ insulin by slow infusion of $0.9 \% \mathrm{NaCl}$, while the patient was eating a standard breakfast. The automated closed-loop intravenous insulin infusion was begun to maintain plasma glucose within physiological limits for the rest of the day. At 22.00 hours the closed-loop system was directed to either the intravenous or intraperitoneal catheter, to maintain plasma glucose at a basal level until 12.00 hours on the next day. Metabolic studies were conducted from 06.00 to 12.00 hours. Randomly selected subjects were infused intraperitoneally; the others were infused intravenously. At 12.00 hours insulin was again infused intravenously by the closed-loop system to maintain plasma glucose within physiological limits. From 22.00 to 12.00 hours on the third day, the insulin infused by the Biostator was directed toward either the intravenous or intraperitoneal catheter via the route not used on the first night of the experiment. The metabolic studies were repeated from 06.00 to 12.00 hours, fol lowing the same protocols.

The metabolic studies were conducted during both periods of intravenous and intraperitoneal closed-loop blood glucose control, following two protocols. The subjects remained in bed and were fasting during isotope infusion. Five subjects completed protocol 1, four completed protocol 2 , and one subject completed both.

\section{Protocol 1: Basal and low rate glucose infusion (Fig. 1)}

After a basal blood sample to determine the natural abundance of isotopic enrichment in plasma glucose, a primed $(4 \mathrm{mg} / \mathrm{kg})$, continuous infusion of $\left[6,6-{ }^{2} \mathrm{H}\right]$ glucose $(2.4 \mathrm{mg} / \mathrm{kg} \cdot \mathrm{h})$ was given from 06.00 to 12.00 hours, using a calibrated syringe pump (Perfusor IV; B.Braun, Melsungen, Germany). Blood samples were collected 
every 15 min between 09.00 and 10.00 hours and the isotopic enrichment of plasma glucose measured, to calculate the basal rate of glucose production. Following this control period, the infusion of labelled glucose was continued together with unlabelled glucose at the rate of $1.5 \mathrm{mg} / \mathrm{kg} \cdot \mathrm{min}$ [28]. Again, blood samples were collected at 15 -min intervals from 11.00 to 12.00 hours. Blood glucose was controlled by the closed-loop insulin infusion, throughout the experimental procedure.

\section{Protocol 2: High rate glucose infusion (Fig. 2)}

The great difficulty encountered in maintaining euglycaemia with intraperitoneal insulin [27] during the infusion of glucose at high rate $(4 \mathrm{mg} / \mathrm{kg} \cdot \min )$ led us to start the glucose infusion several hours before the isotope infusion study. Unlabelled glucose infusion was started at 23.00 hours and continued overnight until 12.00 hours on the following day. $\left[6,6-^{2} \mathrm{H}\right]$ glucose was infused from 08.00 to 12.00 hours at the same rate as in protocol 1 ; blood samples were collected at the beginning and during the last hour of the infusion.

\section{Analytical methods}

All blood samples were centrifuged immediately at $4{ }^{\circ} \mathrm{C}$, and the plasma kept frozen at $-20^{\circ} \mathrm{C}$ until analysed. The glucose concentrations in the plasma, urine and infusate were measured by the glucose oxidase method (Autoanalyzer 2; Beckman Instruments, Fullerton, Calif., USA). Non-esterified fatty acids (NEFA) were determined by the technique of Duncombe [29], $\beta$-hydroxybutyrate by enzymatic assay [30], and lactate by enzymatic ultraviolet assay (Boerhinger Mannheim Lab., Mannheim, Germany). Free and total insulin were separated with polyethylene glycol and measured by radioimmunoassay (INSIK-3 CEA kit; C.I.S. Bio International, Gif-sur-Yvette, France [31]). Immunoreactive C-peptide was determined by a double-antibody method (RIA-mat C-peptide kit; C.I.S. Bio International [32]). Immunoreactive pancreatic glucagon (Glu RIA 50 kit; C.I.S. Bio International), immunoreactive human growth hormone (SB HGH kit; C. I. S. Bio International), and cortisol (Gammer Coat Travenol kit; Sorin Biomedica, Antony, France) were also measured.

The isotopic enrichment of plasma glucose was determined after precipitating plasma proteins and passing the supernatant through anion (Dowex AGI-X8) and cation (Dowex AG50-X8, Bio-Rad Laboratories, Richmond, Calif., USA) exchange columns. The eluate was used to prepare the acetate-boronate derivative for measurement by gas chromatography mass spectrometry $[33,34]$.

\section{Calculation of glucose kinetics}

The parameters of glucose kinetics were calculated from steadystate isotope dilution principles [34]. Thus, when plasma glucose concentration is in a steady state, the turnover of glucose $\left(R_{a}\right)$ can be determined as follows:

$\mathrm{R}_{\mathrm{a}}=\mathrm{i}\left[\frac{\mathrm{E}_{\mathrm{i}}}{\mathrm{E}_{\mathrm{p}}}-1\right]$

where $i$ is the tracer infusion rate, $E_{i}$ and $E_{p}$ are the labelled glucose enrichment in the infusate and the plasma, respectively. In the basal state, the turnover of glucose estimated from the $\left[6,6{ }^{2} \mathrm{H}\right]$ glucose data $\left(\mathrm{R}_{\mathrm{a}}{ }^{2} \mathrm{H}\right)$ equals the true glucose production rate [34]. During infusion with unlabelled glucose, $R_{a}$ is the sum of the rates of endogenous production and exogenous glucose infusion [28]. Therefore, the endogenous production rate is calculated by subtracting the known rate of infusion of unlabelled glucose from the calculated $R_{a}$.

\section{Statistical analysis}

Values are given as mean $\pm \mathrm{SD}$ unless otherwise stated. The parameters of glucose kinetics and the concentrations of substrates and hormones during the intravenous and the intraperitoneal insulin infusions were compared at steady state using Student's paired $t$-test.

\section{Results}

As shown in Tables 1 and 2, plasma glucose was maintained near normal by the closed-loop insulin infusion. In protocol 1, plasma glucose increased slightly with glucose infusion at $1.5 \mathrm{mg} / \mathrm{kg} \cdot \min$ compared to the basal period (Fig. 1). However, the values obtained using intravenous and intraperitoneal insulin were identical (Figs. 1 and 2). During the last hour of each period, when samples were collected for isotope measurements, the mean coefficient of variation for plasma glucose was $3.8-6.1 \%$.

The insulin infusion rates (Fig. 1) required to maintain normoglycaemia when no unlabelled glucose was infused did not differ significantly for the intravenous or intraperitoneal routes of infusion. The overall amounts of insulin infused from 24.00 to 10.00 hours were $32.5 \mathrm{IU}$ for intravenous infusion, coefficient of variation $25.1 \%$, and $28.2 \mathrm{IU}$, coefficient of variation $51.6 \%$, for intraperito-

Table 1. Selected plasma substrate and hormone levels in young Type 1 diabetic men maintained in normoglycaemic steady state with closedloop intravenous or intraperitoneal insulin infusions in the basal state and during the continuous infusion of glucose at $1.5 \mathrm{mg} / \mathrm{kg} \cdot \mathrm{min}$

\begin{tabular}{|c|c|c|c|c|}
\hline & \multicolumn{2}{|l|}{ Basal } & \multicolumn{2}{|c|}{ Glucose infusion $(1.5 \mathrm{mg} / \mathrm{kg} \cdot \mathrm{min})$} \\
\hline & Intravenous & Intraperitoneal & Intravenous & Intraperitoneal \\
\hline Glucose $(\mathrm{mmol} / \mathrm{l})$ & $5.2 \pm 0.1$ & $5.0 \pm 0.1$ & $5.9 \pm 0.1$ & $6.2 \pm 0.1$ \\
\hline Glycerol $(\mathrm{mmol} / \mathrm{l})$ & $0.11 \pm 0.01$ & $0.14 \pm 0.04$ & $0.08 \pm 0.01$ & $0.12 \pm 0.02$ \\
\hline$\beta$-hydroxybutyrate $(\mu \mathrm{mol} / \mathrm{l})$ & $166 \pm 142$ & $82 \pm 31$ & $214 \pm 191$ & $133 \pm 34$ \\
\hline Lactate $(\mathrm{mmol} / \mathrm{l})$ & $0.82 \pm 0.16$ & $0.59 \pm 0.14$ & $0.65 \pm 0.22$ & $0.57 \pm 0.19$ \\
\hline Pyruvate $(\mathrm{mmol} / 1)$ & $0.05 \pm 0.01$ & $0.05 \pm 0.01$ & $0.04 \pm 0.01$ & $0.05 \pm 0.01$ \\
\hline C-peptide (nmol/1) & $0.13 \pm 0.04$ & $0.14 \pm 0.04$ & $0.14 \pm 0.04$ & $0.12 \pm 0.04$ \\
\hline Glucagon $(\mathrm{ng} / \mathrm{ml})$ & $115 \pm 21$ & $124 \pm 22$ & $117 \pm 24$ & $112 \pm 22$ \\
\hline Cortisol $(\mathrm{nmol} / \mathrm{l})$ & $290 \pm 47$ & $366 \pm 39$ & $262 \pm 18$ & $328 \pm 23$ \\
\hline Human growth hormone $(\mu \mathrm{g} / \mathrm{l})$ & $7.3 \pm 2.3$ & $8.4 \pm 3.4$ & $2.9 \pm 1.8$ & $1.9 \pm 0.8$ \\
\hline
\end{tabular}

Values are means \pm SEM 
Table 2. Selected plasma substrate and hormone levels in young Type 1 diabetic men maintained in normoglycaemic steady state with closed-loop intravenous or intraperitoneal insulin infusion during continuous infusion of glucose at $4 \mathrm{mg} / \mathrm{kg} \cdot \mathrm{min}$

\begin{tabular}{lll}
\hline & Intravenous & $\begin{array}{l}\text { Intraperi- } \\
\text { toneal }\end{array}$ \\
\hline Glucose $(\mathrm{mmol} / \mathrm{l})$ & $5.7 \pm 0.1$ & $5.8 \pm 0.1$ \\
Non-esterified fatty acids $(\mu \mathrm{mol} / \mathrm{l})$ & $135 \pm 23$ & $160 \pm 39$ \\
Glycerol $(\mathrm{mmol} / \mathrm{l})$ & $0.04 \pm 0.01$ & $0.05 \pm 0.01$ \\
$\beta$-hydroxybutyrate $(\mu \mathrm{mol} / \mathrm{l})$ & $\mathrm{ND}$ & $\mathrm{ND}$ \\
Lactate $(\mathrm{mmol} / \mathrm{l})$ & $0.58 \pm 0.08$ & $0.39 \pm 0.08$ \\
Pyruvate $(\mathrm{mmol} / \mathrm{l})$ & $0.06 \pm 0.01$ & $0.04 \pm 0.01$ \\
Free insulin $(\mathrm{pmol} / \mathrm{l})$ & $264 \pm 48$ & $252 \pm 16$ \\
C-peptide $(\mathrm{nmol} / \mathrm{l})$ & $0.15 \pm 0.02$ & $0.14 \pm 0.01$ \\
Glucagon $(\mathrm{ng} / \mathrm{ml})$ & $215 \pm 71$ & $198 \pm 61$ \\
Cortisol $(\mathrm{nmol} / \mathrm{l})$ & $255 \pm 5$ & $240 \pm 29$ \\
Human growth hormone $(\mu \mathrm{g} / \mathrm{l})$ & $2.5 \pm 1.5$ & $1.8 \pm 0.6$ \\
\hline
\end{tabular}

Values are means \pm SEM. ND, Not detectable

Table 3. Whole body glucose kinetics $(\mathrm{mg} / \mathrm{kg} \cdot \mathrm{min})$ in young Type 1 diabetic men maintained in normoglycaemic steady state by closedloop intravenous or intraperitoneal insulin infusion

\begin{tabular}{lll}
\hline Glucose kinetic parameters & Intravenous & Intraperitoneal \\
\hline Basal & $2.37 \pm 0.26$ & $1.71 \pm 0.14^{\mathrm{a}}$ \\
$\begin{array}{l}\text { Glucose infusion } \\
1.5 \mathrm{mg} / \mathrm{kg} \cdot \mathrm{min}\end{array}$ & \\
$\quad$ Turnover & $2.38 \pm 0.18$ & $1.99 \pm 0.10^{\mathrm{a}}$ \\
$\quad$ Hepatic production & $0.88 \pm 0.18$ & $0.49 \pm 0.23^{\mathrm{a}}$ \\
$4 \mathrm{mg} / \mathrm{kg} \cdot \mathrm{min}$ & & \\
$\quad$ Turnover & $4.56 \pm 0.12$ & $4.31 \pm 0.10^{\mathrm{a}}$ \\
$\quad$ Hepatic production & $0.56 \pm 0.12$ & $0.31 \pm 0.10^{\mathrm{a}}$ \\
\hline
\end{tabular}

${ }^{a}$ Significantly different from the intravenous insulin infusion at the $p<0.05$ level.

Values are means \pm SEM

neal infusion. During the last hour of the basal period, the intravenous insulin infusion rate was $0.71 \pm 0.24 \mathrm{mU} /$ $\mathrm{kg} \cdot \mathrm{min}$, and the intraperitoneal rate was $0.68 \pm 0.33 \mathrm{mU} /$ $\mathrm{kg} \cdot \mathrm{min}$, respectively (Fig.1). Both routes of infusion produced plasma free insulin levels that were not significantly different (Table 1). During glucose infusion at $1.5 \mathrm{mg} /$ $\mathrm{kg} \cdot \mathrm{min}$, the intravenous insulin infusion rate was $1.33 \pm$ 0.24 , while the intraperitoneal infusion rate was $1.80 \pm$ $0.75 \mathrm{mU} / \mathrm{kg} \cdot \min$ (Fig. 1, $p>0.05$ ), but the plasma free insulin levels were not significantly different (Table 1). During the $4 \mathrm{mg} / \mathrm{kg}$ - min glucose infusion, $74.8 \mathrm{IU}$ was infused intravenously and $106.3 \mathrm{IU}$ was infused intraperitoneally between 24.00 and 12.00 hours. The coefficient of variation was greater for the intraperitoneal route $(42.8 \%)$ than for the intravenous route $(13.1 \%)$. The rates of insulin infusion (Fig. 2) during the last hour of this experiment were $1.74 \pm 0.46 \mathrm{mU} / \mathrm{kg} \cdot \mathrm{min}$ (intravenous) and $2.94 \pm 0.90 \mathrm{mU} / \mathrm{kg} \cdot \mathrm{min}$ (intraperitoneal). However, the difference was not significant and the plasma free insulin levels were almost identical for the two routes of infusion (Table 2).

The concentrations of the various plasma substrates and hormones in the basal state and during the low rate glucose infusion are shown in Table 1. Plasma NEFA and glycerol tended to be higher, and $\beta$-hydroxybutyrate and lactate tended to be lower with the intraperitoneal route. However, none of the differences attained statistical significance. Plasma glucagon, cortisol and growth hormone showed only small non-significant differences between the intravenous and intraperitoneal routes. The plasma substrate and hormone concentrations were virtually identical with both routes of insulin infusion during the infusion of glucose at $4 \mathrm{mg} / \mathrm{kg} \cdot \min$ (Table 2).

Endogenous glucose production was derived from the $\left[6,6{ }^{2} \mathrm{H}\right]$ glucose dilution in plasma. The mean coefficients of variation of plasma glucose enrichments were $5 \%$, $4.2 \%$ and $4 \%$ with intravenous insulin, and $5.9 \%, 3.2 \%$ and $5.7 \%$ with intraperitoneal insulin, during the basal period and the 1.5 and $4 \mathrm{mg} / \mathrm{kg}$. min unlabelled glucose infusion, respectively. Basal postabsorptive glucose production was significantly lower with the intraperitoneal route than with the intravenous route of insulin infusion (Table $3, p<0.05$ ). The glucose turnover rate remained lower with the intraperitoneal route during the infusion of glucose at $1.5 \mathrm{mg} / \mathrm{kg} \cdot \mathrm{min}$. Consequently, the residual hepatic glucose production during this low rate of glucose infusion was significantly lower with the intraperitoneal insulin infusion (Table 3, $p<0.05$ ). The glucose turnover rate, during the infusion of glucose at $4 \mathrm{mg} / \mathrm{kg} \cdot \min$, was also lower with intraperitoneal infusion than with the intravenous insulin infusion. Similarly, the residual hepatic glucose production was lower with the intraperitoneal route (Table $3, p<0.05$ ).

\section{Discussion}

The present study evaluates the relative contributions of hepatic glucose production and peripheral tissue disposal to the maintenance of normoglycaemia in Type 1 diabetic patients given intraperitoneal infusions of insulin. Previous animal studies have used intraportal rather than the intraperitoneal insulin infusions, which is a more direct way of estimating the effects of insulin on the liver and the periphery. However, some studies have indicated that the intraportal route provided better control of the hepatic glucose production, and thus of the plasma glucose level, than the peripheral route $[12,14,19,21]$. Other studies have shown no difference between the two routes of insulin infusion [11, 13,15, 18, 20]. Recent studies using multiple rates of insulin infusion and the euglycaemic clamp technique [35] in dogs suggest that the regulation of hepatic glucose production correlates to the same degree with the peripheral as with the portal insulin concentration $[17,23]$.

The clinical relevance of metabolic effects of intraportal insulin concerns mainly pancreas $[19,21]$ and islet [20] transplants. The intraperitoneal route is the important one for the continuing use of implanted pumps $[2,3]$ and the anticipated mechanical beta cell [35]. The published data suggest that it is difficult to study the metabolic advantages of intraperitoneal insulin infusion in humans. First, hepatic glucose production is regulated by a narrow range of insulin infusion rates, which corresponds to very small changes in peripheral insulin concentration [36]. Secondly, it may not be possible to measure hepatic glu- 
cose production with sufficient precision during non-constant glucose infusion [37]. Thirdly, the pharmacokinetics of intraperitoneal insulin are very different from those of intravenous insulin [27], and glucose fluxes must be measured under circumstances which are not dependent on this factor. The experimental protocol was therefore designed so that measurements were taken in glycaemic and isotopic steady states and during constant rates of glucose infusion, which optimises the precision for measuring hepatic glucose production. The results show that these conditions were met in the postabsorptive state and during the infusion of glucose at two different rates, one below the estimated basal glucose production and one slightly above this rate. Plasma glucose concentrations and isotopic enrichments showed small coefficients of variation during the periods of measurement of glucose turnover. Variations for insulin infusion were greater with intraperitoneal insulin than with intravenous infusion several hours before the metabolic studies, due to the great difficulties in controlling blood glucose with intraperitoneal closed-loop insulin [27].

In the postabsorptive state, both routes of insulin infusion ensured normoglycaemia with similar rates of insulin infused by the closed-loop system. Differences in peripheral free insulin levels were quite small, but previous experience has shown that they do not accurately reflect differences at low insulin infusion rates [38]. Hepatic glucose production was $28 \%$ lower with intraperitoneal infusion than with intravenous insulin infusion. These results support the hypothesis that plasma glucose is normalized by a preferential action on hepatic glucose production. Consequently, less glucose was disposed of by the peripheral tissues in the experimental conditions. The higher NEFA and lower $\beta$-hydroxybutyrate concentrations with intraperitoneal infusion tend to support this higher hepatic lower peripheral action of insulin. However, the differences were not significant, possibly due to the small number of experimental subjects, and conclusions on this particular point should be made with caution. Other studies in dogs have shown that the effect of intraportal insulin on plasma glucose control was either greater $[12,14,21]$ or not different $[11,39-43]$ than with the intravenous route. As peripheral insulin concentrations were lower with intraportal insulin in these dog experiments, it was concluded that peripheral glucose uptake was lower, and that the hepatic effect should be greater, as in the present study. However, no differences in basal hepatic glucose output were found with the intraportal and the peripheral routes of insulin administration in diabetic dogs controlled by a closed-loop system [13-16] or in diabetic rats with transplanted islets [20]. In addition, recent studies [17,23] have suggested that peripheral rather than portal insulin is correlated with the regulation of hepatic glucose production.

The rate of insulin infusion was slightly higher with intraperitoneal insulin, during the infusion of glucose at $1.5 \mathrm{mg} / \mathrm{kg} \cdot \mathrm{min}$. However, the difference was not significant and the peripheral free insulin levels were comparable. Glucose turnover did not change from basal with the intravenous route, indicating that hepatic glucose production was suppressed by an amount equal to the glucose infused. The residual hepatic production with the intraperitoneal route was still lower than with intravenous insulin; NEFA levels tended to be higher and $\beta$-hydroxybutyrate lower, which was also found in the fasting state. It could be argued that hepatic glucose production was suppressed less than expected, i.e. $1.5 \mathrm{mg} / \mathrm{kg} \cdot \mathrm{min}$, but this was due to the fact that basal hepatic glucose production was lower than we could have predicted and during infusion with $1.5 \mathrm{mg} / \mathrm{kg} \cdot \mathrm{min}$ glucose, hepatic glucose production was already maximally suppressed, as compared to normal subjects [28]. Consequently, the overall glucose turnover was slightly increased. With a higher rate of glucose infusion, $4 \mathrm{mg} / \mathrm{kg} \cdot \mathrm{min}$, the maximal suppression of hepatic glucose production was still accurately measured. The residual glucose production with intravenous insulin was comparable to values for normal subjects [28]. The rate of insulin infusion required to maintain normoglycaemia overnight was approximately $40 \%$ greater with intraperitoneal insulin, but the peripheral insulin concentrations from the two routes of insulin infusion did not differ. Thus, at comparable peripheral insulin levels, residual hepatic glucose production with intraperitoneal insulin was $55 \%$ of that with intravenous insulin.

In conclusion, our results tend to support the hypothesis that normoglycaemia is better maintained with intraperitoneal insulin infusion in Type 1 diabetic patients as it has a greater effect on hepatic glucose production than the intravenous infusion.

Acknowledgements. We are very grateful to the subjects who agreed to participate in these demanding studies. We greatly appreciate the contribution of the nursing staff of the Herold and Saint-Louis Hospitals. We also thank Professor J. -L. Selam for editorial assistance. This study was supported by grants from the Fondation pour la $\mathrm{Re}$ cherche Médicale, the Fonds d'Etude du Corps Médical des Hôpitaux de Paris and the Aide aux Jeunes Diabétiques.

\section{References}

1. Selam JL, Slingeneyer A, Hedon B, Mares P, Beraud JJ, Mirouze $J$ (1983) Long-term ambulatory peritoneal insulin infusion of brittle diabetes with portable pumps: comparison with intravenous and subcutaneous routes. Diabetes Care 6: 105-111

2. Irsigler K, Kritz H, Hagmuller G et al. (1981) Long-term continuous intraperitoneal insulin infusion with an implanted remotecontrolled insulin infusion device. Diabetes 30: 1072-1075

3. Selam JL, Charles MA (1990) Devices for insulin administration. Diabetes Care 13: 955-979

4. Schade DS, Eaton RP, Davis T et al. (1981) The kinetics of peritoneal insulin absorption. Metabolism 30: 149-155

5. Nelson JA, Stephen R, Landou ST, Wilson DE, Tyler FH (1982) Intraperitoneal insulin administration produces a positive portal-systemic blood insulin gradient in unanesthetized unrestrained swine. Metabolism 31:969-972

6. Radziuk J, Pye S, Davies G, Seigler D, Reeves M (1988) Splanchnic and systemic absorption of intraperitoneal insulin. Diabetes Res Clin Pract 5 [Suppl 1]: 24A (Abstract)

7. Selam JL, Bergman RN, Raccah D, Jean-Didier N, Lozano J, Charles MA (1990) Determination of portal insulin absorption from peritoneum via novel nonisotopic method. Diabetes 39 : $1361-1365$

8. Felig P, Wahren J (1971) Influence of endogenous insulin secretion on splanchnic glucose and amino acid metabolism in man. $\mathrm{J}$ Clin Invst 50: 1702-1711 
9. Blackard WG, Nelson NC (1970) Portal and peripheral vein immunoreactive insulin concentrations before and after glucose infusion. Diabetes 19:302-306

10. Beylot M, Khalfallah Y, Laville M et al. (1987) Insulin-mediated glucose disposal in type 1 (insulin-dependent) diabetic subjects treated by continuous subcutaneous or intraperitoneal insulin infusion. Diabete Metab 13: 450-456

11. Botz CK, Leibel BS, Zingg W, Gander RE, Albisser AM (1976) Comparison of peripheral and portal routes of insulin infusion by a computer-controlled insulin infusion system (artificial endocrine pancreas). Diabetes 25:691-700

12. Stevenson RW, Parsons JA, Alberti KGMM (1981) Comparison of the metabolic responses to portal and peripheral infusions of insulin in diabetic dogs. Metabolism 30: 745-752

13. Fischer U, Rizza RA, Hall LD et al. (1982) Comparison of peripheral and portal venous insulin administration on postprandial metabolic responses in alloxan-diabetic dogs. Effects of identical preprogrammed complex insulin infusion waveforms. Diabetes 31:579-584

14. Stevenson RW, Parsons JA, Alberti KGMM (1983) Effect of intraportal and peripheral insulin on glucose turnover and recycling in diabetic dogs. Am J Physiol 244: E190-195

15. Ishida T, Chap Z, Chou J et al. (1984) Effects of portal and peripheral venous insulin infusion on glucose production and utilization in depancreatized, conscious dogs. Diabetes 33: 984-990

16. Freyse EJ, Fischer U, Albrecht G, Marx S, Keilacker H (1987) The effect of prehepatic insulin administration on alanine flux rates in diabetic dogs. Diabetologia 30: 402-408

17. Ader M, Bergman RN (1990) Peripheral effects of insulin dominate suppression of fasting hepatic glucose production. Am J Physiol 258: E1020-E1032

18. Kryshak EJ, Butker PC, Marsh C et al. (1990) Pattern of postprandial carbohydrate metabolism and effects of portal and peripheral insulin delivery. Diabetes 39: 142-148

19. Brown J, Mullen Y, Clark WR, Molnar IG, Heininger D (1979) Importance of hepatic portal circulation for insulin action in streptozotocin-diabetic rats transplanted with fetal pancreases. J Clin Invest 64: 1688-1694

20. Kruszynska YT, Home PD, Alberti KGMM (1985) Comparison of portal and peripheral insulin delivery on carbohydrate metabolism in streptozotocin-diabetic rats. Diabetologia 28: 167-171

21. Albisser AM, Nomura M, Greenberg GR, McPhedran NT (1986) Metabolic control in diabetic dogs treated with pancreatic autotransplants and insulin pumps. Diabetes 35: 97-100

22. Duckworth WC, Saudeck CD, Henry RR (1992) Why intraperitoneal delivery of insulin with implantable pumps in NIDDM? Diabetes 41: 657-661

23. Giacca A, Fisher SJ, Shi ZQ, Gupta R, Lickley HLA, Vranic M (1992) Importance of peripheral insulin levels for insulin-induced suppression of glucose production in depancreatized dogs. J Clin Invest 90: 1769-1777

24. Shishko PI, Kovalev PA, Goncharov VG, Zajarny IU (1992) Comparison of peripheral and protal (via the umbilical vein) routes of insulin infusion in IDDM patients. Diabetes 41: 10421049

25. Bouanick B, M'Bemba J, Chevalier A, Robert JJ, Slama G, Selam JL (1992) Insulin administered intraperitoneally and intravenousiy suppress identically hepatic glucose production at matched systemic levels. Diabetologia 35 [Suppl 2]: A37 (Abstract)

26. Rolland-Cachera MF, Cole TJ, Sempé M, Tichet J, Rossignol C, Charraud A (1991) Body mass index variations: centiles from birth to 87 years. Eur J Clin Nutr 45: 13-21

27. Leblanc H, Chauvet D, Lombrail P, Robert JJ (1986) Glycemic control with closed-loop intraperitoneal insulin in type I diabetes. Diabetes Care 9: 124-128
28. Wolfe RR, Allsop JR, Burke JF (1979) Glucose metabolism in man: responses to intravenous glucose infusion. Metabolism 28: 210-219

29. Duncombe WG (1964) The colorimetric micro-determination of non-esterified fatty acids in plasma. Clin Chim Acta 9: 122-125

30. Williamson DH, Mellanby J, Krebs HA (1962) Enzymatic determination of $\mathrm{D}(-)$ beta-hydroxybutyric acid and aceto acetic acid in blood. Biochem J 82: 90-95

31. Kyzuya H, Blix PM, Horwitz DL, Steiner DF, Rubenstein AH (1977) Determination of free and total insulin and C-peptide in insulin-treated diabetics. Diabetes 26: 22-29

32. Kaneko T, Oko H (1974) Radioimmunoassay of human proinsulin and C-peptide using synthetic human connecting peptide. Endocrinol Jpn 21: 141-144

33. Wiecko J, Sherman WR (1976) Boroacetylation of carbohydrates. Correlations between structure and mass spectral behavior in monoacetylhexose cyclic boronic esters. J Am Chem Soc 98: 7631-7637

34. Bier DM, Sherman WR, Arnold KJ, Holland WH, Holmes WF, Kipnis DM (1977) Measurement of "true" glucose production rates in infancy and childhood with 6,6-dideuteroglucose. Diabetes 26: 1005-1015

35. Schade DS, Eaton RP (1980) The peritoneum. A potential insulin delivery route for a mechanical pancreas. Diabetes Care 3: 229-234

36. Rizza R, Mandarino L, Gerich J (1981) Dose-response characteristics for effects of insulin on production and utilization of glucose in man. Am J Physiol 240: E630-E639

37. Finegood DT, Bergman RN, Vranic M (1987) Estimation of endogenous glucose production during hyperinsulinemic-euglycemic glucose clamps. Comparison of unlabeled and labeled exogenous glucose infusates. Diabetes 36: 914-924

38. Darmaun D, Cirillo D, Koziet J, Chauvet D, Young VR, Robert JJ (1988) Whole body glucose kinetics in type I diabetes studied with $\left(6,6-{ }^{2} \mathrm{H}\right)$ and $\left(\mathrm{U}-{ }^{13} \mathrm{C}\right)$ glucose and the artificial B-cell. Metabolism 37: 491-498

39. Madison LL, Unger RH (1958) The physiologic significance of the secretion of endogenous insulin into the portal circulation: comparison of the effects of glucagon-free insulin administered via the portal vein and via a peripheral vein on the magnitude of hypoglycemia and peripheral glucose utilization. J Clin Invest 37 : 631-639

40. Poulsen JSD, Smith M, Deckert M, Deckert T (1980) Comparison of intraperitoneal, intraportal and intravenous insulin infusion. Acta Endocrinol 95: 500-504

41. Rizza RA, Westland RE, Hall LD et al. (1981) Effect of peripheral versus portal venous administration of insulin on postprandial hyperglycemia and glucose turnover in alloxan-diabetic dogs. Mayo Clinic Proc 56: 434-438

42. Shoemaker WC, Mahler R, Ashmore J (1959) The effect of insulin on hepatic glucose metabolism in the anesthetized dog. Metabolism 8: 494-511

43. Starzl TE, Scanlan WA, Yanof HM et al. (1963) A comparison of the hypoglycemic effect of insulin with systemic venous and portal venous administration. J Surg Res 3:293-300

Received: 29 March 1993

and in revised form: 14 June 1993

Professor J. -J. Robert

Unité d'Endocrinologie et Diabétologie de l'Enfant

Hôpital des Enfants Malades

149 rue de Sèvres

F-75015 Paris

France 